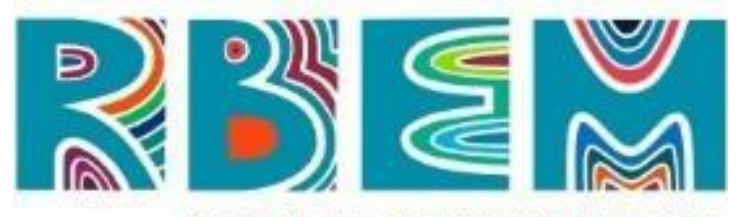

BEVISTA BAIANA DE EDUCAÇAO MATEMATICA

\title{
ARTIGO
}

de

https://doi.org/10.47207/rbem.v1i.10240

\section{Reflexões sobre os desafios para a aprendizagem matemática na Educação Básica durante a quarentena}

\author{
SANTOS, Marcele da Silva \\ SEEDUC-RJ/SEMED-Macaé. Mestra em Práticas da Educação Básica pelo Colégio Pedro II. \\ ORCID: https://orcid.org/0000-0002-1403-8259. E-mail: marcemarcelemarce @ g mail.com. \\ SANT'ANNA, Neide da Fonseca Parracho \\ Colégio Pedro II. Doutora em Educação pela Pontifícia Universidade Católica (PUC-Rio). \\ ORCID: https://orcid.org/0000-0002-2142-1547. E-mail: neidefps@gmail.com.
}

\begin{abstract}
Resumo: O objetivo do artigo é suscitar reflexões sobre possíveis desafios para o ensino e a aprendizagem matemática na Educação Básica durante a quarentena, devido à COVID19. Foi desenvolvido a partir das diretrizes legais educacionais criadas para validar a substituição das aulas presenciais por aulas em meios digitais enquanto durar a situação de pandemia, atentando para a diferenciação do ensino remoto emergencial e o ensino a distância, diante deste fato de inédita ocorrência na Educação Básica. Discorremos sobre as dificuldades encontradas pelos alunos nesse momento onde o ensino está sendo realizado de forma remota. Abordamos através da análise de referencial teórico e de situações reais a superação dos docentes e a importância da formação continuada e tecnológica do professor. Sugerimos possibilidades para aprendizagens significativas nesse contexto atual. E destacamos a necessidade de enfrentamento do problema com a aplicação de políticas públicas educacionais que promovam a igualdade de oportunidades, a equidade.

Palavras-chave: Aprendizagem. Educação Matemática. Ensino Remoto. Tecnologias.
\end{abstract}

\section{Reflections on the challenges for math learning in Basic Education during quarantine}

\begin{abstract}
The article aims to raise reflections on possible challenges for mathematics teaching and learning in Basic Education during quarantine due to COVID19. It was developed based on the educational legal guidelines created to validate the substitution of face-to-face classes with classes in digital media while the pandemic situation lasts, paying attention to the differentiation of emergency remote education and distance learning, in view of this unprecedented fact in Basic Education. The difficulties encountered by students while teaching is being done remotely are discussed. Through analysis of the theoretical framework and real situations, the overcoming and the importance of continuous and technological training of teachers are approached. Possibilities for meaningful learning in this context are suggested. Besides, the need to face the problem with equity, i. e., with the application of public educational policies that promote equal opportunities, is highlighted.
\end{abstract}

Keywords: Learning. Mathematical Education. Remote Teaching. Technologies. 


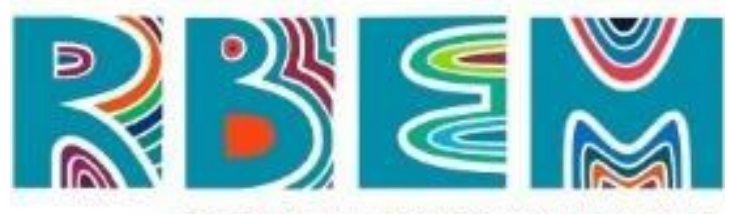

REVISTA BAIANA DE EDUCAÇAO MATEMATICA

\section{Reflexiones sobre los desafíos del aprendizaje matemático en Educación Básica durante la cuarentena}

Resumen: El objetivo del artículo es plantear reflexiones sobre los posibles desafíos para la enseñanza y el aprendizaje de las matemáticas en Educación Básica durante la cuarentena, debido al COVID19. Se desarrolló a partir de los lineamientos legales educativos creados para validar la sustitución de clases presenciales por clases en medios digitales mientras dure la situación de pandemia, prestando atención a la diferenciación entre educación remota de emergencia y educación a distancia, ante este hecho inédito en la Educación Básica. Hablamos de las dificultades que encuentran los estudiantes en ese momento cuando la enseñanza se realiza de forma remota. A través del análisis del marco teórico y situaciones reales, abordamos la superación de los docentes y la importancia de la formación continua y tecnológica de los docentes. Sugerimos posibilidades de aprendizaje significativo en este contexto actual. Y destacamos la necesidad de enfrentar el problema con la aplicación de políticas públicas educativas que promuevan la igualdad de oportunidades, la equidad.

Palabras-Clave: Aprendizaje. Educación Matemática. Enseñanza remota. Tecnologías.

\section{Introdução}

O mundo foi surpreendido com o imprevisto de uma pandemia. Diante da ameaça à vida, que é um direito fundamental, em 11 de março a Organização Mundial de Saúde (OMS), recomendou, dentre outras, o distanciamento social como medida para controlar o problema. O Ministério da Saúde declarou emergência em saúde pública na Portaria $\mathrm{n}^{\circ} 188$, e estados e municípios suspenderam as atividades escolares.

As escolas foram fechadas após menos de dois meses do início letivo de 2020, sem previsão para retorno. A Organização das Nações Unidas para a Educação, a Ciência e a Cultura (UNESCO) revelou no final de março que pouco mais de 1,5 bilhões de estudantes do mundo estavam fora da sala de aula devido à COVID-19 (ONU, 2020). E se posicionou favorável a continuidade de vínculo com a aprendizagem e trabalho à distância.

Em outros países, onde a suspensão ocorreu antes, foi adotado o ensino remoto. Essas circunstâncias exigiram algumas adaptações na rotina de professores e alunos. Algumas Secretarias de Educação do país buscaram alguma adequação inspirada em outros modelos, antes mesmo de um posicionamento oficial do Ministério da Educação (MEC).

Um fato alarmante percebido foi a primeira necessidade dos alunos ser referente à alimentação fora da escola, a urgência da fome. O ensino e a aprendizagem ficaram para 


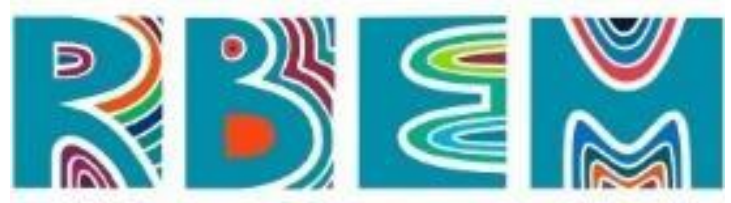

REVISTA BAIANA DE EDUCAÇA MATEMATICA

segundo plano, talvez. Questionamos ao que minimamente vem sendo oferecido aos alunos nas escolas públicas pelo país para que a igualdade ou equidade seja promovida.

O planejamento pode ser considerado como um dos requisitos para o desenvolvimento de um bom trabalho ao ensinar. A elaboração de um plano permite que a escola, o professor, determinem as etapas do processo, as ferramentas necessárias para cada momento e delineiem os objetivos a serem alcançados ao longo do ano letivo. A ausência de diretrizes nacionais durante este período dificultou a organização, o planejamento e a execução para a validação pedagógica. Atrasou o estabelecimento de um planejamento interno das escolas para $\mathrm{o}$ atendimento às necessidades específicas do alunado.

A Educação Básica não estava preparada logisticamente, nem os profissionais formativamente, para esta demanda imediata de adequação ao ensino remoto, antes da paralisação das aulas presenciais, $88 \%$ dos professores nunca tinha dado aula à distância de forma remota, e, além disso, $83 \%$ declararam que não se sentiam preparados. Este dado foi obtido através da pesquisa quantitativa por meio de um survey online e de amostra por conveniência, realizada pelo Instituto Península com 2,4 mil docentes da Educação Básica em todo o Brasil.

$\mathrm{Na}$ maior parte das realidades educacionais não há vinculação dos avanços tecnológicos ao processo de ensino em situações habituais. A ausência de uma cultura digital e as desigualdades educacionais e sociais nas redes públicas de ensino agravam a situação para resolução paliativa do problema, constituindo obstáculos para a execução de um plano efetivo.

O Ensino de Matemática presencial possui suas especificidades e desafios. Quando pensamos nesse ensino numa situação atípica como a que estamos vivendo, outros desafios ainda maiores ocorrem, desde o domínio no manuseio de ferramentas tecnológicas, adequação de metodologias de ensino, seleção de conteúdos com maior relevância, até extensão do acesso a todos os alunos das turmas em ambientes virtuais de aprendizagem e por videoconferências que possibilitariam uma maior interação e outras situações que tornam a lista extensa.

É importante não confundir a educação remota com a educação a distância (EAD). A educação a distância, surgiu oficialmente pelo Decreto $\mathrm{n}^{\circ} 5.622$ de 19 de dezembro de 2005 . E com posterior atualização através do Decreto $n^{\circ}$ 9.057, de 25 de maio de 2017. Não nos 


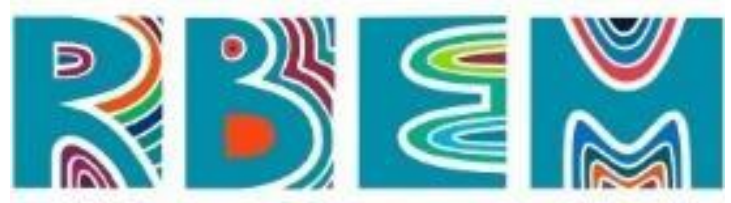

REVISTA BAIANA DE EDUCACAO MATEMATICA

preparamos para o oferecimento de um ensino em um ambiente virtual. A construção de um curso EAD depende de planejamento estratégico, da criação de um designer instrucional, seja através de apostilas ou ferramentas tecnológicas e, nesse caso, a possibilidade para acesso ao conteúdo por parte dos alunos incentivada por políticas de acesso.

Sendo a Base Nacional Comum Curricular (BNCC) o documento norteador para o atingimento de uma educação de qualidade de acordo com as necessidades e pluralidades presentes no território nacional, recorremos ao seu conteúdo para encontrar caminhos possíveis para este momento.

Os professores têm uma demanda imediata por soluções para estas questões. Para atendê-la, este artigo suscita um espaço para reflexões acerca desta problemática. Nesse sentido, buscamos examinar o atual momento de ensino e aprendizagens na Educação Matemática.

\section{Diretrizes legais criadas}

Em 17 de março de 2020, o MEC, se manifestou através da Portaria $\mathrm{n}^{\circ}$ 343, sobre a substituição das aulas presenciais por aulas em meios digitais enquanto durar a situação de pandemia. Posteriormente, foi realizada alteração com a Portaria $n^{\circ} 345$, em 19 de março, Portaria $\mathrm{n}^{\mathrm{o}}$ 356, em 20 de março e Portaria $\mathrm{n}^{\mathrm{o}}$ 473, em 13 de maio. Esses documentos referiam-se apenas ao Ensino Superior, não sendo mencionada a Educação Básica em nenhum deles. Todas as portarias citadas foram revogadas pela Portaria $\mathrm{n}^{\mathrm{o}} 544$, em 17 de junho de 2020, tratando o mesmo assunto.

Em $1^{\mathrm{o}}$ de abril, o Governo Federal publicou a Medida Provisória $\mathrm{n}^{\mathbf{0}}$ 934, estabelecendo normas excepcionais sobre o ano letivo da Educação Básica para o enfrentamento da situação de emergência. $\mathrm{O}$ documento apenas dispensava o cumprimento da obrigatoriedade de observância ao mínimo de dias de efetivo trabalho escolar, desde que fosse cumprida a carga horária anual, não elucidava o fato de como fazer acontecer o ensino.

Em 17 de abril, foi publicado um edital de chamamento, o Conselho Nacional de Educação (CNE), através de consulta pública buscava dialogar e encontrar novos caminhos para a continuidade e a reorganização das atividades pedagógicas não presenciais em todos os níveis, etapas e modalidades. 


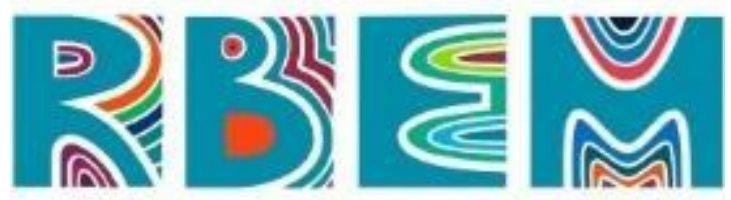

REVISTA BAIANA DE EDUCAÇA MATEMATICA

Em 30 de abril, após quatro dias de reunião ordinária, o CNE produziu o Parecer CNE/CP n5/2020, aprovado por unanimidade. Segundo este documento, as atividades não presenciais poderiam ser consideradas letivas neste período de pandemia para fins de cumprimento da carga horária mínima anual. Este parecer deu origem ao Parecer $\mathrm{CNE} / \mathrm{CP}$ n9/2020, homologado pelo MEC em 09 de julho, e complementado pelo Parecer CNE/CP $\mathrm{n}^{\circ} 11 / 2020$ homologado parcialmente pelo MEC em 3 de agosto.

O CNE demonstra, nesses documentos, preocupação com as formas de reduzir os impactos de longa duração da suspensão das atividades educacionais de forma presencial, sendo evidenciada a atenção com a garantia de padrões básicos de qualidade na aprendizagem no tocante a evitar o crescimento de desigualdades educacionais e, ainda, com o atendimento das competências e objetivos previstos na BNCC. Amparado na legislação educacional e na própria BNCC, menciona a possibilidade de reordenação da programação curricular, aumento dos dias letivos e da carga horária do ano subsequente para cumprimento dos objetivos de aprendizagem e desenvolvimento do ano letivo anterior, ressalvados os casos dos estudantes que se encontram nos anos finais.

No que se refere especificamente às recomendações sobre o Ensino Fundamental, anos finais, e Ensino Médio, foi sugerida a elaboração de sequências didáticas, estudos dirigidos, pesquisas, projetos, entrevistas, experiências, simulações, realização de atividades on-line síncronas e ofertas de atividades on-line assíncronas de acordo com as possibilidades tecnológicas, programas educativos em TV aberta, vídeos educativos por meio de plataformas digitais sem a necessidade de conexão simultânea, utilização de mídias sociais de longo alcance, sob a supervisão dos responsáveis. Estas recomendações estendem-se sobre a Educação de Jovens e Adultos (EJA).

Traz a possibilidade de pós-pandemia, um retorno gradual com a presença física de alunos e profissionais da educação nas unidades de ensino, seguindo as recomendações das autoridades sanitárias. E, ainda, a atenção ao acolhimento e reintegração social dos professores, alunos e suas famílias. São apontados, como forma de superar os impactos psicológicos do longo período de isolamento social, diálogos e trocas de experiências.

Recomendam ainda, no retorno, uma avaliação diagnóstica, que deverá ser definida por cada sistema de ensino, considerando suas especificidades, entre outros pontos de total relevância. 


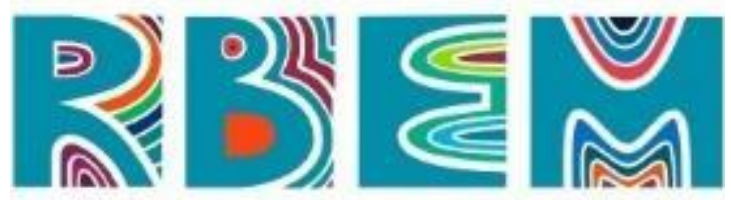

REVISTA BAIANA DE EDUCAÇA MATEMATICA

Em 18 de agosto foi sancionada a Lei $\mathrm{n}^{\mathrm{o}}$ 14.040, originada pela conversão da Medida Provisória 934, ressalvados alguns vetos. Apesar dos avanços que essa sanção traz, os vetos referentes ao apoio financeiro aos Estados e Municípios de forma supletiva na implementação de medidas necessárias para o retorno das escolas causa preocupação. Estamos diante de um problema que envolve inúmeras variáveis, e precisa ser resolvido num coletivo. A solução não funcionará se cada um tiver que resolver na medida de suas possibilidades. Quando vidas de alunos e professores podem estar em risco, preservá-las é inegociável.

\section{Dificuldades dos alunos no ensino remoto}

Repentinamente os alunos precisaram se adaptar a um novo normal. A rotina quase metódica de ir para a escola, sentar à mesa, participar das aulas, e a possibilidade de desenvolver habilidades cognitivas e consciência social, ao interagir presencialmente com os colegas no recreio e sala, momentaneamente foram suspensas (CIFUENTES-FAURA, 2020).

As realidades podem ser contrastantes dentro de uma escola, quanto mais em um país com tantas variedades culturais, regionais e sociais. Garantir, no atual momento, as mesmas condições para que os alunos desenvolvam habilidades como consta no art. 206 da Constituição Federal torna-se um desafio.

Existem fatores internos e externos nos lares que podem influenciar de forma positiva ou negativa. O suporte familiar e a participação na educação dos filhos são essenciais para respostas positivas, mas há casos onde os pais não possuem estudos e outros ainda precisam se ausentar para trabalhar em busca do sustento, sendo a criança ou adolescente responsável por cuidar dos afazeres domésticos e dos irmãos mais novos. É uma realidade em que, em muitos casos, pode faltar a estrutura logística mínima, como a alimentação, ou até mesmo um local com uma mesa e cadeira para que o aluno possa realizar uma rotina de estudo.

O ensino remoto foi adequado a cada situação particular, através de vídeos, apostilas, ambientes de aprendizagem virtual, videoconferência, entre outros.

O celular, temido e proibido em muitas escolas antes da pandemia, se tornou uma ferramenta didática com a aplicabilidade de multiplicar conhecimentos e trazer solução para que o ensino dos alunos se tornasse possível nesse momento. O acesso a esta tecnologia ou outras, como tablet e computador, não é realidade de uma parte expressiva da população. 


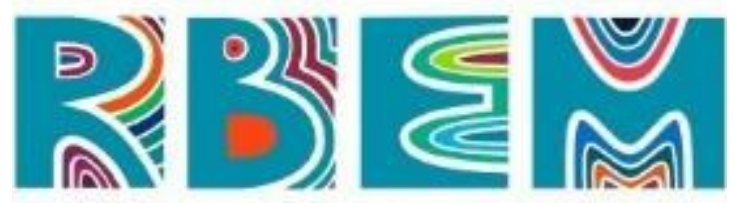

REVISTA BAIANA DE EDUCAÇA MATEMATICA

Além disso, a conectividade para participação de videoconferências ou envio dos conteúdos pedagógicos é um outro elemento que dificulta o recebimento das informações e esclarecimento de dificuldades que possam surgir.

Um outro empecilho são as dificuldades técnicas no manuseio das ferramentas para o desenvolvimento de tarefas, fato curioso já que os alunos são nativos digitais, possuem natural familiaridade com as últimas tecnologias digitais (KAMPF, 2011). Em sua grande maioria, eles não são ensinados a explorar as potencialidades didáticas de seus dispositivos eletrônicos, na maior parte das vezes utilizados para redes sociais e aplicativos sem esta função. Não podemos deixar de listar como dificuldade a própria falta de maturidade para lidar com a exposição que a rede traz.

\section{Formação tecnológica e continuada do professor}

O mundo globalizado é dinâmico e muito veloz, as informações chegam num instante e no segundo seguinte já são obsoletas. Esse mesmo fenômeno acontece com as ferramentas tecnológicas. Acompanhar esse fluxo não é uma tarefa simples.

Ainda existe um receio dos professores quando o assunto é tecnologia, algo totalmente normal, o novo pode causar esse efeito paralisante e o medo. São inúmeros os motivos dados para justificar repulsa e resistência à adequação pedagógica mediada por tecnologias. Destacamos, principalmente, a negligência no oferecimento de políticas públicas para acesso aos meios de inclusão e cultura digital nas escolas.

A última década já vinha sinalizando a necessidade de adequação das práticas pedagógicas como resposta ao desenvolvimento tecnológico atual. A escola manteve quase os mesmos métodos do século passado, isso não significa que fosse ruim para aquele tempo. Mas, hoje, não atende às demandas para a formação do cidadão que viverá nas próximas décadas.

Partindo da ideia de que a educação exerce forte influência nas transformações da sociedade, temos pressa para que a escola acompanhe esses avanços (DIAS; PINTO, 2019). Não obstante, a escola e a formação do professor não acompanharam o desenvolvimento tecnológico. Ao contrário, o descompasso vem-se agravando há algum tempo. A sociedade 


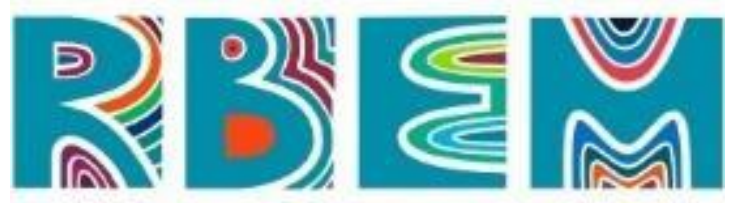

REVISTA BAIANA DE EDUCAÇA MATEMATICA

avançou em outros aspectos e permaneceu quase estática na incorporação de tecnologias educacionais.

Existem tantas situações relacionadas à oferta de condições mínimas para acesso e permanência dos estudantes na escola que a formação continuada do professor, e as condições logísticas para serem colocados em prática os conhecimentos no ensino, acaba não sendo priorizada.

Segundo Tjara (2012), “a incorporação das novas tecnologias de comunicação e informação nos ambientes educacionais provoca um processo de mudança contínuo, não permitindo mais uma parada, visto que as mudanças ocorrem cada vez mais rapidamente e em curtíssimo espaço de tempo". Essa ação reflete naturalmente no ambiente escolar e demanda adequação dos métodos adotados para promover o ensino.

A pandemia trouxe a necessidade de transformações rápidas e urgentes para o ensino realizado de forma remota. Uma grande crise acelerou o processo de adequação das práticas pedagógicas mediadas pelas tecnologias e fez com que os professores avançassem décadas em meses (MACHADO, 2020). É obvio que não atingiu a totalidade de alunos nem de professores, mas foi o início de um novo momento para a Educação, e apresenta indícios de possível ocorrência do ensino híbrido no pós-pandemia.

O conhecimento e formação continuada no que tange práticas mediadas por tecnologias, algumas vezes sequer oferecidas para o professor, foram desenvolvidos a partir das próprias habilidades e das redes de conhecimento. A pesquisa já mencionada neste artigo, realizada pelo Instituto Península, destaca que em abril e maio, 74\% dos professores gostariam de treinamento para o ensino à distância.

Os professores, dentro de cada realidade e possibilidade, tiveram a necessidade de pesquisar e explorar as ferramentas, aprender a manuseá-las e adequá-las a cada situação adotando o uso de métodos variados no ensino: slides, vídeos gravados a partir do próprio celular, vídeos caseiros produzidos com computador, celular e câmeras pessoais, lousa/mesa digitalizadora, chat síncrono, perguntas respondidas de forma assíncrona, videoconferências que permitem a interação próxima à que acontece na sala de aula, diferentes plataformas de aprendizagem, ferramentas dinâmicas para perguntas e respostas como quizzes, softwares dinâmicos, apostilas, e outros tantos, até recursos improvisados. 


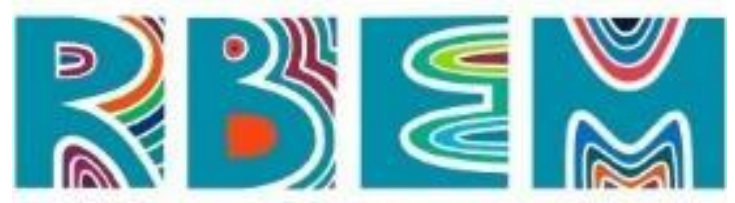

REVISTA BAIANA DE EDUCAÇA MATEMATICA

É importante destacar que apesar da variedade de ferramentas, se não houver planejamento e aplicação adequada destas para cada situação específica, não faz sentido para $\mathrm{o}$ aluno. $\mathrm{O}$ equipamento tecnológico e a acessibilidade não produzem aprendizagem por si sós, dependem que os processos sejam mediados e orientados para alcançar os objetivos. Nessa perspectiva, a presença do professor é indiscutivelmente imprescindível.

Esse momento trouxe uma enxurrada de informações novas no que diz respeito aos objetos de aprendizagem, como se fosse suficiente o simples manuseio das ferramentas, sendo muitas vezes desconsiderado o percurso para um ensino objetivado.

É importante refletir a prática para não incidir nesse ato falho.

É momento de experimentar. As descobertas estão sendo feitas juntamente com os alunos. Errar, acertar e ajustar será muitas vezes necessário fazer, até que sejam alcançados resultados próximo dos esperados. Muitos professores estão se sobrecarregando numa tentativa de dar conta de todo esse avanço tecnológico, algo impossível. A realidade atual para a maioria, nem se aproxima daquela presencial. Talvez, uma alternativa seja utilizar ferramentas simples e acessíveis que permitam o armazenamento em nuvem e a colaboração dos alunos. Os editores de texto, as planilhas eletrônicas e de apresentação de slides. Talvez não seja o esperado como recomendação neste artigo, mas com o planejamento adequado

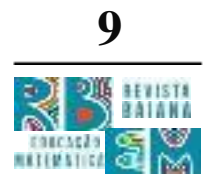
podem ser suficientes para tornar o ambiente virtual um espaço para construção a partir das experiências.

O pós-pandemia não excluirá imediatamente o ensino remoto, provavelmente teremos o desafio de integrá-lo ao ensino presencial, ensino híbrido. Foi dado um "start" e não partiremos do mesmo ponto em que paramos. (PASINI; CARVALHO; ALMEIDA, 2020)

É importante a capacidade para o autodesenvolvimento docente, mas não podemos romantizar as situações que exigiram do professor adequação imediata sem as condições mínimas e deixar de cobrar o apoio dos órgãos responsáveis para que tornem possível essa formação antecipada de forma continuada. 


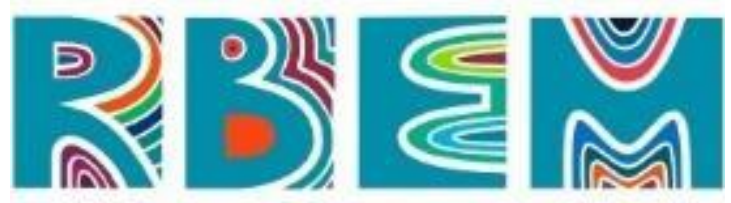

REVISTA BAIANA DE EDUCAÇA MATEMATICA

\section{A Aprendizagem Significativa nesse contexto}

Diante do contexto de pandemia é um avanço ter a possibilidade de continuar promovendo aprendizados e refletir sobre como podem acontecer, mesmo com as escolas físicas fechadas.

É uma preocupação a situação de aprendizagem, quanto mais agora que ensino e aprendizagem se encontram em adaptação diante dos desafios. Os professores sentem a angústia de não poderem fazer o conhecimento chegar a todos os alunos de suas turmas da mesma maneira, poder oferecer feedback e troca mesmo que assíncrona. E, ainda, naqueles onde o ensino é síncrono, surgem questionamentos, sobre o que de fato é relevante ensinar no momento e quais aprendizagens e habilidades devem ser desenvolvidas. O grande problema é que não temos respostas objetivas no momento, e as ações precisam ser imediatas.

Sugere-se que o mais apropriado seja recorrer ao documento com orientações norteadoras que determina as competências gerais e específicas, as habilidades e as aprendizagens essenciais que devem ser desenvolvidas pelos alunos durante a Educação Básica, a BNCC.

Outra orientação a ser seguida é a busca da aprendizagem significativa. A teoria da aprendizagem significativa, que teve como grande precursor David Ausubel (AUSUBEL, 2000), aponta que os alunos produzem sentidos e significados acerca de suas aprendizagens introduzidos em contextos. Essa abordagem da aprendizagem abre um espaço para maior protagonismo de quem está aprendendo.

O ensino remoto foi a solução temporária dada no momento. Nesse sentido, podemos ceder espaço para que o aluno promova sua aprendizagem de forma significativa, ao permitir uma maior autonomia no desenvolvimento de novas habilidades fornecendo um direcionamento através da leitura de reportagens com temas da atualidade e de relevância, ao explorar a interpretação dos dados apresentados, através da escrita e do pensamento crítico, fundamentado na matemática crítica que capacita a compreensão de fenômenos, sociais, políticos e econômicos e dos aspectos ligados a justiça social, incentivando os alunos a refletir sobre assuntos urgentes para a sociedade.

A visão da aprendizagem significativa leva a fomentar processos mais dinâmicos e interessantes para o aluno, que suscitem a curiosidade, a criatividade, desafiando-os e permitindo o trabalho colaborativo na resolução de situações problemas. Podendo recorrer 


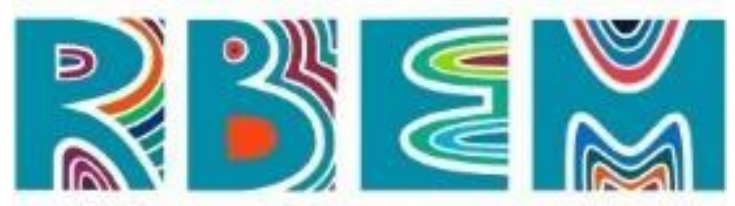

REVISTA BAIANA DE EDUCAÇAO MATEMÁTICA

ainda, ao uso de metodologias ativas de ensino (MATTAR,2017) que se adequem ao momento para promover essas aprendizagens; a sala de aula invertida (PEREIRA; DA SILVA, 2018), o estudo de casos para a resolução de problemas (MELO, 2020), os recursos audiovisuais (DOS SANTOS; GONÇALVES, 2017), a utilização de jogos (DO CARMO; MARCO, 2019), tecnologias (PRENSKY,2001), a gamificação (FARDO, 2013) e o trabalho em equipe/grupos, são alguns exemplos.

O quadro abaixo sugere alguns desses instrumentos que podem ser utilizados para a promoção do ensino remoto emergencial.

\section{QUADRO 1: RECURSOS TECNOLÓGICOS PARA AULAS REMOTAS}

\begin{tabular}{|l|l|}
\hline \multicolumn{1}{|c|}{ RECURSOS } & \multicolumn{1}{|c|}{ FUNCIONALIDADE } \\
\hline $\begin{array}{l}\text { Google Docs (documentos, planilhas, } \\
\text { apresentações) }\end{array}$ & $\begin{array}{l}\text { Compartilhar (documentos, planilhas, } \\
\text { apresentações), trabalhar em grupo e } \\
\text { socializar. }\end{array}$ \\
\hline $\begin{array}{l}\text { Dropbox, Google drive, Onedrive } \\
\text { https://www.dropbox.com/pt_BR/ } \\
\text { https://www.google.com.br/drive/apps.html }\end{array}$ & $\begin{array}{l}\text { Compartilhamento de documentos e vídeos (os } \\
\text { arquivos ficam armazenados em nuvem) }\end{array}$ \\
\hline $\begin{array}{l}\text { Mentimeter } \\
\text { https://www.mentimeter.com/ }\end{array}$ & $\begin{array}{l}\text { Interação e compartilhamento das informações } \\
\text { coletadas em tempo real } \\
\text { (enquetes, nuvem de palavras, perguntas) }\end{array}$ \\
\hline $\begin{array}{l}\text { Kahoot } \\
\text { https://kahoot.com/ }\end{array}$ & $\begin{array}{l}\text { Criação de jogos de aprendizado, testes de } \\
\text { múltipla escolha }\end{array}$ \\
\hline $\begin{array}{l}\text { Socrative } \\
\text { https://www.socrative.com/ }\end{array}$ & $\begin{array}{l}\text { Elaboração de } \\
\text { avaliação/revisão com resultados e relatórios } \\
\text { instantâneos e engajamento por equipes. }\end{array}$ \\
\hline $\begin{array}{l}\text { Padlet } \\
\text { https://pt-br.padlet.com/ }\end{array}$ & $\begin{array}{l}\text { Elaboração de murais e painéis virtuais } \\
\text { colaborativos. }\end{array}$ \\
\hline $\begin{array}{l}\text { Phet } \\
\text { https://phet.colorado.edu/pt_BR/ }\end{array}$ \\
\hline
\end{tabular}

Fonte: Elaborado pelas autoras 


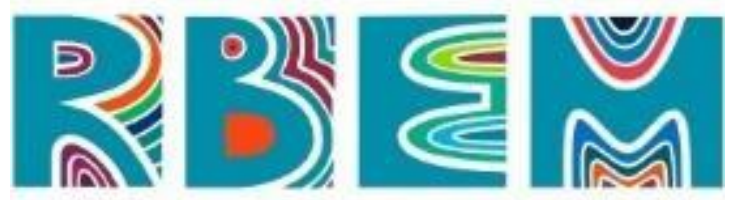

REVISTA BAIANA DE EDUCAÇAO MATEMATICA

Não funcionará acumular material com inúmeros conteúdos e arquivos. Talvez seja mais relevante buscar engajar os conteúdos mais relevantes num contexto a partir de temáticas interdisciplinares. Assim, talvez seja suficiente para o momento concentrar esforços em promover uma abordagem unificada das diversas áreas de conhecimento numa direção de trabalhar competências gerais.

O Google docs e outras ferramentas similares que tenham as mesmas funcionalidades podem ser usados para realização de tarefas em grupo. A partir de reportagens abordando temas da atualidade, como por exemplo, sustentabilidade, desigualdades sociais, saúde pública, fome, desemprego, dados relacionados a fatores econômicos, agravados com a situação de pandemia. É possível explorar elementos matemáticos através das informações textuais, dos dados em tabelas e gráficos. As informações textuais também podem ser convertidas utilizando elementos matemáticos. É extremamente interessante esse processo porque desmistifica a imagem limitada de que em matemática apenas se fazem cálculos. É possível pensar criticamente as situações que experimentamos em nossa realidade inserindo a linguagem matemática, numa tentativa de compreender melhor os acontecimentos e estimular o aluno a investigar, refletir e buscar compreender elementos imbuídos na sociedade da qual faz parte. O professor tem a tarefa de provocar fundamentado na matemática crítica ao inserir esses elementos combinados ao conteúdo específico que pretende ensinar. Para isso, é necessária pesquisa e planejamento anterior à execução da atividade.

As atividades nesse formato geram uma ampla gama de desdobramentos. Permitem que os alunos utilizem sua criatividade e apresentem resultados, às vezes, além do esperado pelos professores. Precisamos estar receptivos para os diversos caminhos escolhidos pelos alunos. Isto pode, sim, ser trabalhoso. Assim como numa resolução de um exercício, onde todos chegam a um resultado, mas podem usar caminhos e soluções diferenciadas, podem aparecer diferentes abordagens para o mesmo objetivo final.

Cabe ressaltar que diversas ferramentas didáticas podem ser combinadas para uma mesma atividade. Por exemplo, a utilização do Mentimeter para a realização de um brainstorming, onde os alunos contribuem de forma espontânea no intuito de resolver algum problema ou de realizar alguma tarefa conjunta. 


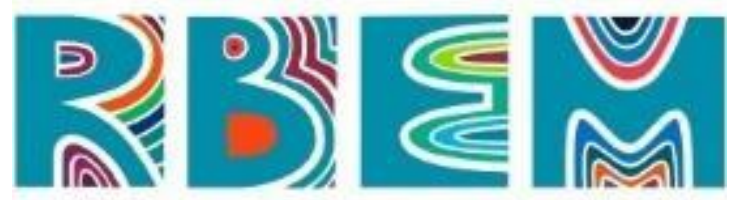

REVISTA BAIANA DE EDUCAÇA MATEMATICA

Há ainda a possibilidade de criar o engajamento dos alunos em equipe utilizando o Socrative para verificar se determinada habilidade foi desenvolvida. A rapidez dos resultados individuais e do grupo fornecidos pela ferramenta agiliza o trabalho do professor para apresentar aos alunos um feedback.

Muitos são os caminhos possíveis. Explorar as ferramentas e conhecer suas possibilidades auxiliam o professor a selecionar o melhor para cada situação que propõe.

\subsection{Sugestão de atividade}

A atividade aqui sugerida foi aplicada em uma turma de $7^{\circ}$ ano. A aplicação depende de que os alunos tenham um computador, tablet ou celular conectados à internet para a aula síncrona através de videoconferência, mas também pode ser realizada de forma assíncrona sem a colaboração. Talvez não tenha aplicabilidade em algumas situações, como por exemplo, quando os alunos não possuem a acessibilidade, infelizmente.

Incentivar a participação dos alunos nas aulas presenciais é sempre um desafio para o professor. Enquanto alguns pedem para mostrar sua solução, ir ao quadro resolver um exercício de forma espontânea, outros são tímidos, têm pavor de errar na frente da turma. É tarefa do professor encaminhar essas situações, mostrando aos alunos que tanto o acerto quanto o erro podem ser caminhos para a aprendizagem, e ajudando-os a perceber este último com mais naturalidade para que se sintam mais confiantes enquanto aprendem.

Com o ensino remoto, a falta de interação pessoal diminuiu a possibilidade de participação nesses moldes. O aluno participa menos, há ruídos que fazem com que o microfone permaneça desligado durante a explicação até que se possa perguntar, e outros fatores que conhecemos. A atividade foi pensada para além do conteúdo, mas também para promover uma maior interação entre os alunos e no sentido de dinamizar a participação e execução de uma tarefa em grupo, mesmo que a distância.

Muitas são as possibilidades didáticas para a adaptarmos às nossas aulas através de videoconferência. Devemos ter clareza de que qualquer que seja a proposta, o planejamento e os objetivos a alcançar antecedem a execução, e são necessários para a escolha adequada das ferramentas e tarefas.

A atividade contempla a competência geral "exercitar a curiosidade intelectual, e recorrer à abordagem própria das ciências incluindo a investigação, a reflexão, a análise 


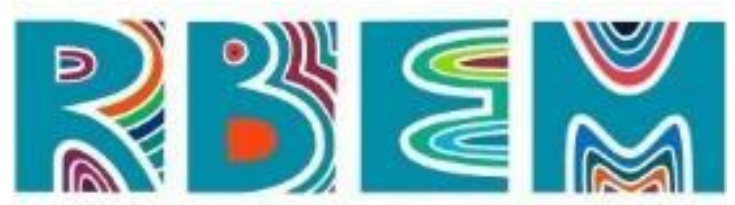

REVISTA BAIANA DE EDUCAÇAO MATEMÁTICA

crítica" (BNCC, p.9) e as competências específicas de propiciar "desenvolver o raciocínio lógico, o espírito de investigação" e "interagir com seus pares de forma cooperativa, trabalhando coletivamente no planejamento e desenvolvimento de pesquisas para responder questionamentos e na busca de soluções de problemas" (BNCC, p.267). E ainda as habilidades (EF07MA03; EF07MA04) referentes a resolução de problemas envolvendo operações com números inteiros.

Foi construída uma pirâmide numérica no programa de Planilhas Google, similar ao Excel que muitos conhecem. Na construção, foi utilizada lógica de programação na própria entrada das células da planilha, com os resultados esperados. É um exercício de grande incidência em livros didáticos e a primeira etapa exige que os alunos identifiquem alguma lógica para o preenchimento dos demais blocos não preenchidos (Figura 1).

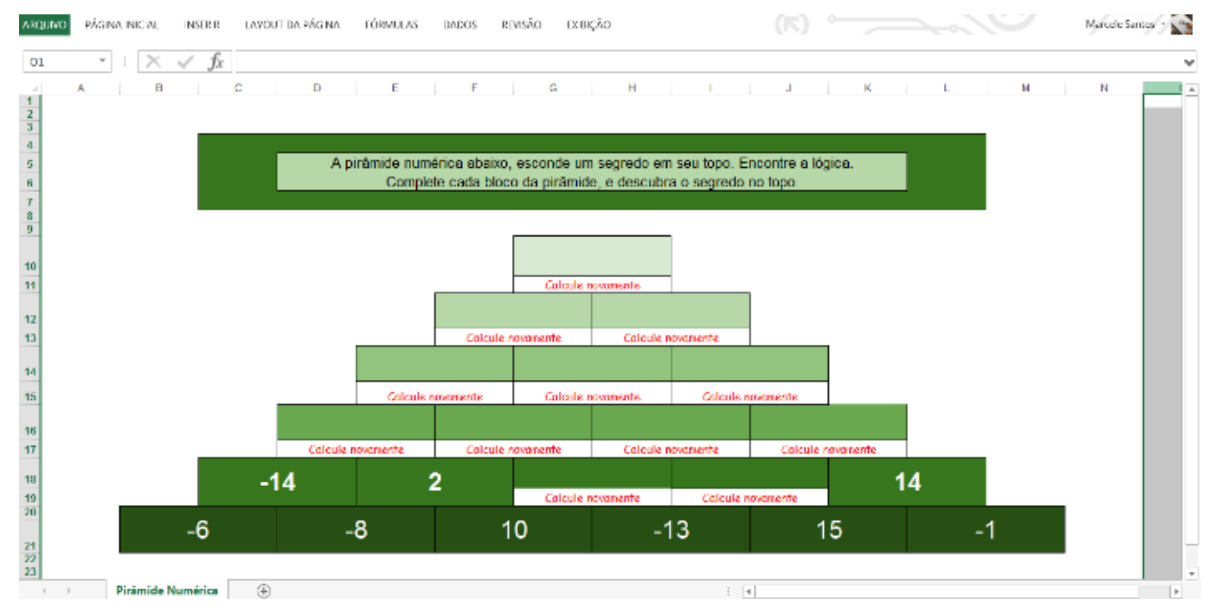

Figura 1: Atividade proposta

Para compartilhar com os alunos a tarefa e permitir que participassem da edição, acrescentando as respostas, foi necessário realizar alguns ajustes, detalhados abaixo.

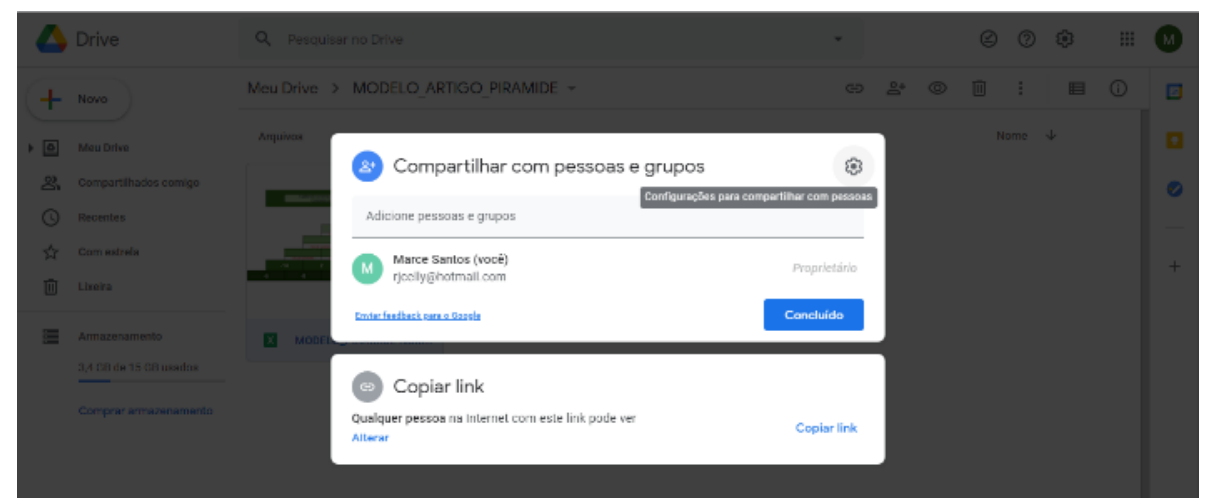

Figura 2: Compartilhamento com os alunos 


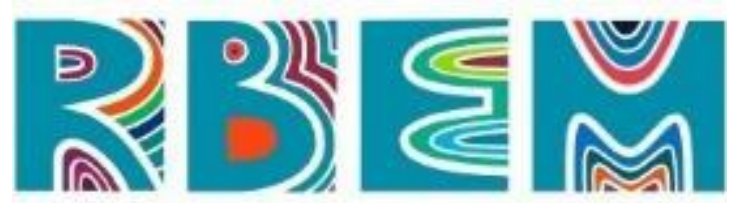

$\mathrm{O}$ arquivo deve estar carregado no Google Drive. Ao, com o botão direito, clicar na opção "compartilhar", se abrirá caixa (ver a imagem representada na Figura 2) onde se poderão incluir os emails dos alunos que terão a permissão para editar, ou copiar o link que também pode ser localizado na Figura 2. Este pode também ser disponibilizado em chat ou por outra forma de comunicação com os alunos.

Outro detalhe muito importante é a definição da permissão para que os alunos possam colaborar com a edição, como mostrado na Figura 3.

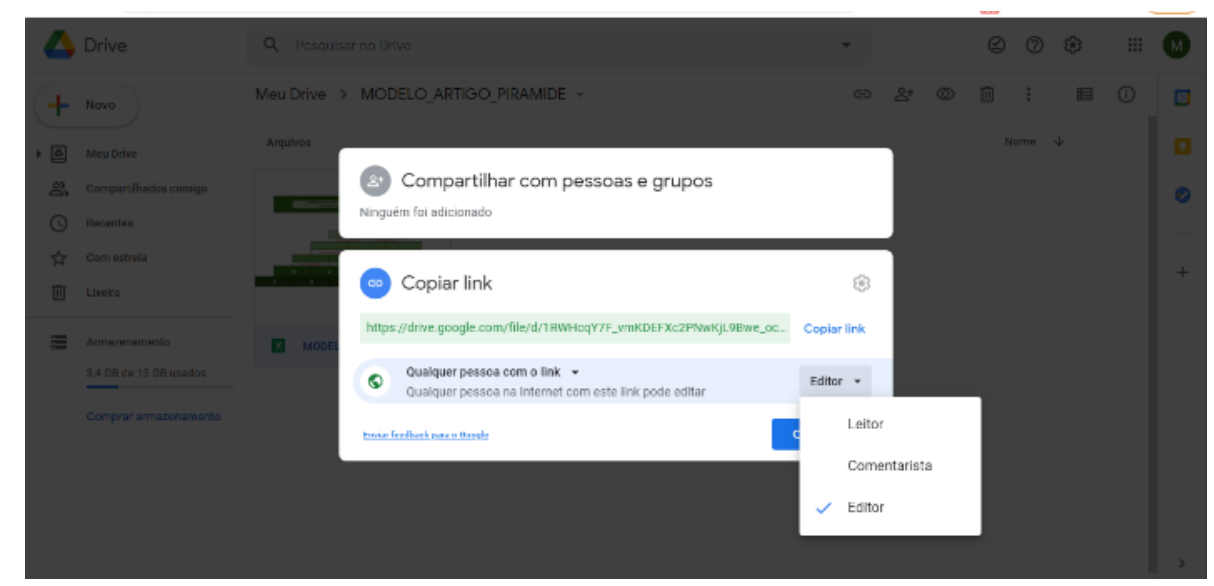

Figura 3: Definição de compartilhamento. Leitor. Comentarista. Editor

Todas as alterações ficam registradas, com o nome, dia e horário que ocorreram e versões anteriores podem ser recuperadas em histórico, caso ocorra algum problema.

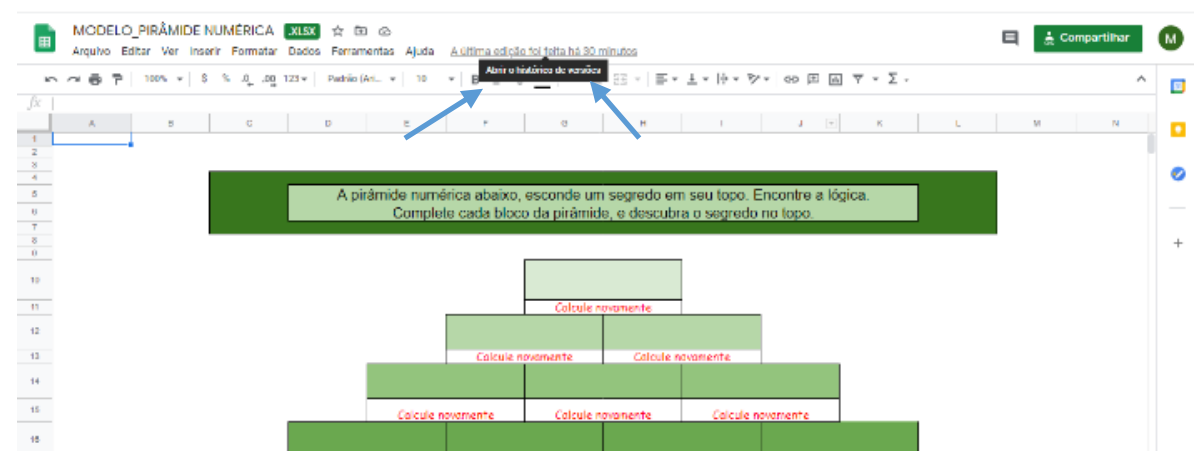

Figura 4:Visualização do histórico

A dinâmica aconteceu da seguinte maneira. Inicialmente, os alunos tiveram um tempo para descobrir a lógica. Aos poucos, foram sinalizando que haviam encontrado a lógica, 


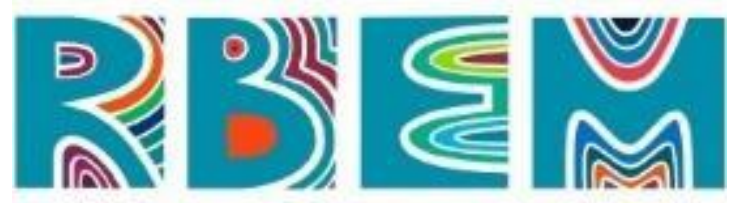

REVISTA BAIANA DE EDUCAÇAO MATEMÁTICA

outros não conseguiam achar nenhum padrão. Então, os alunos foram convidados a expor o raciocínio para o grupo. Houve erros e acertos na explanação, e o tempo todo houve a mediação da professora com provocações matemáticas. Após a lógica ser entendida, foram um por um colaborando na planilha. Enquanto não acertassem, a mensagem que aparecia era "calcule novamente". Houve casos onde o aluno errou, e foi interessante porque tivemos a oportunidade de trabalhar a teoria, repassar o conteúdo, exemplificar, até que tudo foi preenchido corretamente.

Os alunos ficaram entusiasmados com a atividade e participaram ativamente do início ao fim.

Caso haja interesse em aplicar ou entender melhor o funcionamento da planilha, o arquivo é disponibilizado. Basta fazer o download para editar e compartilhar com os alunos.

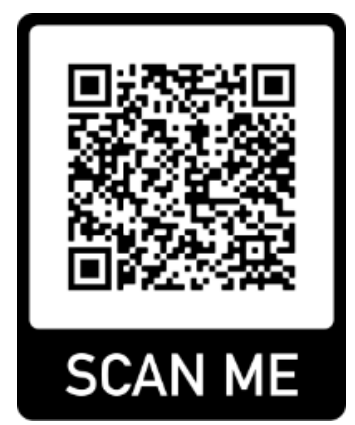

Figura 5: QR code para acesso ao arquivo da atividade

A Figura 5 mostra outra possibilidade de compartilhamento. Basta apontar a câmera do celular que a imagem irá redirecionar para o arquivo compartilhado pelo Google Drive.

Como produz esse QR code? Existem algumas possibilidades na internet. Utilizamos o site <https://br.qr-code-generator.com> (Figura 6) e colamos o link indicado pela Figura 2. Ele gera uma imagem, fizemos o download e ela foi disponibilizada. 


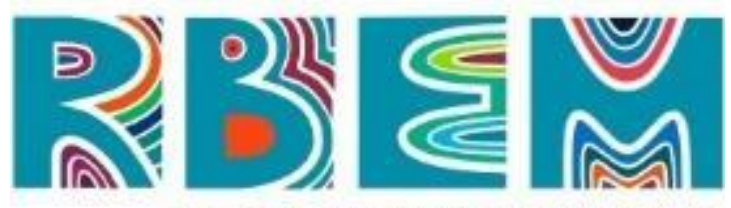

REVISTA BAIANA DE EDUCAÇAO MATEMATICA

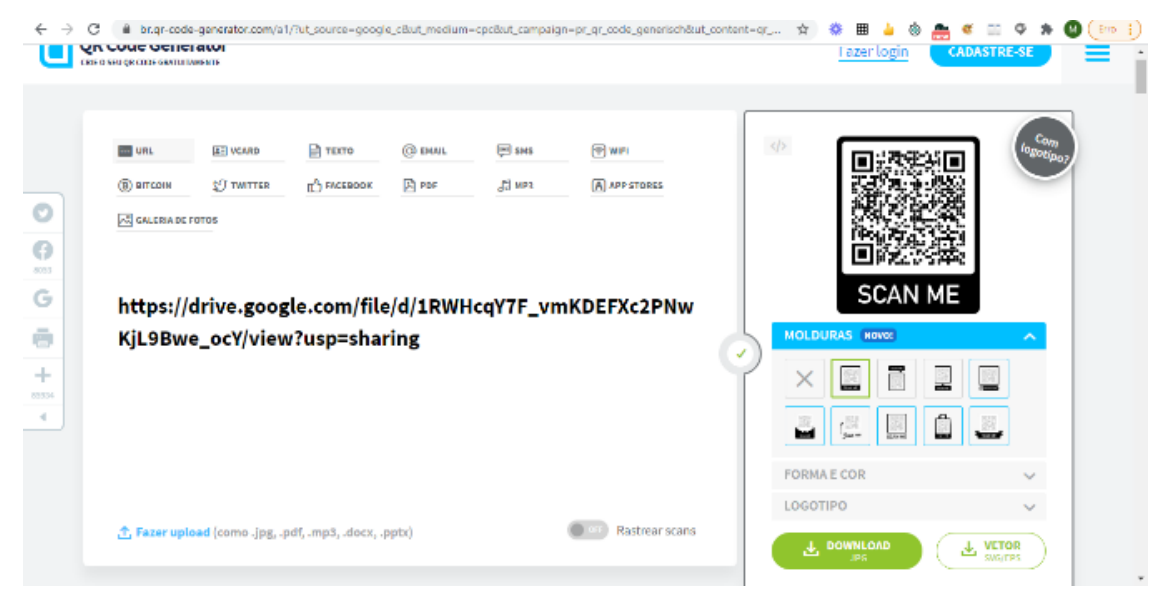

Figura 6: Criando o QR code

Qualquer mídia pode ser disponibilizada dessa forma, vídeo, áudio, documento em nuvem, entre outros.

Como se pode perceber as possibilidades são inúmeras. A partir da pequena contribuição desta prática já realizada, verifica-se que uma atividade simples pode oferecer inúmeras oportunidades de ampliar a participação dos alunos, ao ceder a partilha de um espaço para as construções e a organização de raciocínios individuais e do grupo. Destaca-se, ainda, como já sinalizado, a escolha por ferramentas já conhecidas como Planilhas Google, ou outra similar, que podem ser boas opções na hora de planejar uma tarefa para a aula remota.

\section{Considerações Finais}

A pandemia é um problema que vem sendo enfrentado pelo mundo, e aqui no Brasil estamos tendo que reorganizar e adaptar a nossa realidade enquanto a vacina não estiver disponível ou não se estabelecerem medidas de segurança que garantam a defesa da vida.

Mesmo com as escolas fechadas, professores e alunos não cruzaram os braços, tiveram mais uma vez a oportunidade de mostrar sua força e resistência, produzindo ensino e aprendizagens, seja mediada por tecnologias ou através de materiais impressos. Os responsáveis também merecem destaque, pois também sabemos que muitos estão acumulando a função de supervisionar os filhos no ensino às tarefas domésticas e ao seu próprio trabalho. 


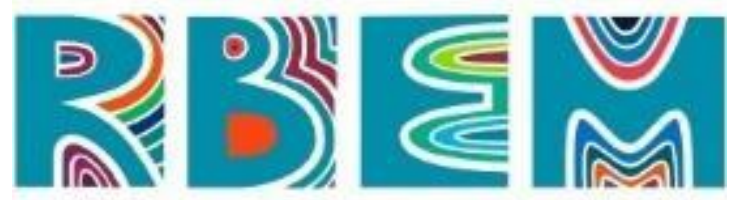

REVISTA BAIANA DE EDUCAÇAO MATEMÁTICA

Esse momento de crise que estamos enfrentando serviu para acelerar a adequação e inserção da cultura digital no ensino. A escola, por necessidade, precisou renovar sua forma de alcançar os alunos. É óbvio que ainda não atingiu a totalidade, mas o passo inicial foi dado e não haverá retrocesso, porque o avanço tecnológico é contínuo.

Causa muita preocupação o ensino de Matemática nesse momento, porque muitos alunos não possuem as mesmas condições para acesso às aulas e a possibilidade de retirar suas dúvidas com os professores. O avanço do conteúdo pode ser realizado mais rapidamente, mas é imprudente, por que quantidade não significa qualidade. Sabemos o desafio que enfrentamos em situações normais e, numa situação atípica como a atual, o excesso de informações, levando a assimilação indevida, pode dificultar aprendizagens posteriores.

Por este motivo, acreditamos que práticas pedagógicas que tenham como objetivo o desenvolvimento de competências e habilidades gerais e a seleção de algumas competências e habilidades específicas de acordo com o ano de escolaridade, que incentivem a colaboração a partir de ferramentas tecnológicas, quando possível, sejam alternativas melhor sucedidas.

Hoje, a aprendizagem envolve redes de interação on-line e off-line compostas por pessoas, tecnologias e informação e pode ocorrer em situações formais (sala de aula) ou informais (na web ou situações cotidianas). Temos a tarefa de orientar nossos alunos a filtrar as informações relevantes e confiáveis para seu desenvolvimento.

Podemos esperar de um pós-pandemia a necessidade de integração de aulas presenciais e remotas, aulas híbridas. Teremos alunos com maior protagonismo, segurança para lidar com a tecnologia, pesquisas e realização de tarefas. E, por outro lado, alunos que não tiveram a oportunidade de desenvolver essas habilidades.

Outro aspecto que precisa ser apontado é a ausência do contato social para o desenvolvimento das aprendizagens. Ficou evidente que nenhuma tecnologia ou material substitui a presença de um professor, o olho no olho, a interação pessoal. Acreditamos que ocorra maior reconhecimento dos professores, e da importância de práticas bem planejadas para o ensino, seja presencial ou remoto. E ansiamos que estes tenham apoio logístico e possibilidades para realizar formação continuada nas redes de ensino. 


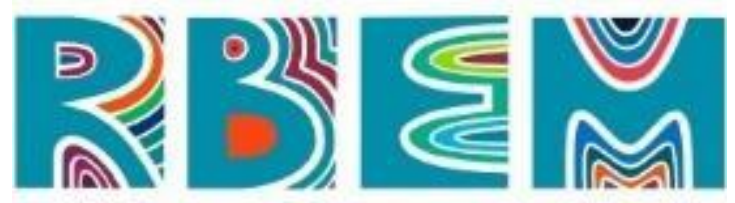

REVISTA BAIANA DE EDUCAÇAO MATEMÁTICA

Devemos ser pacientes com aqueles profissionais que ainda não estão no mesmo ritmo, precisam de acolhimento e auxílio para não se sentirem inferiores e isso não causar desconforto.

Alertamos para a própria perspectiva romantizada do docente sendo visto como herói em meio a uma pandemia mundial, na mídia, ao desvincular a humanização do indivíduo professor, este como qualquer outro profissional, merece respeito e condições mínimas logísticas para desempenhar seu ofício.

Causa preocupação que os alunos em situações mais vulneráveis acabem perdendo a motivação para estudar e retomar as aulas presenciais.

Esta pandemia pode provocar impactos e desgastes psicológicos nos alunos e professores que passaram a enfrentar diariamente uma série de fatores estressantes com a duração prolongada do confinamento, a falta de contato com pessoas, o medo de ser ou ter algum parente infectado, a falta de espaço e recursos em casa.

Por estas e outras, precisamos reforçar a imprescindibilidade de políticas públicas para o enfrentamento e solução de questões que ultrapassem as questões pedagógicas, que não dependam apenas dos professores e da escola.

Nota. O presente artigo foi expandido a partir de uma versão inicial, apresentada no IX Seminário de Pesquisa em Educação Matemática do Rio de Janeiro e publicada nos Anais do IX SPEM.

\section{Referências}

AUSUBEL, David. P. The Acquisition and Retention of Knowledge: A Cognitive View. Springer: Dordrecht, 2000.

BRASIL. Lei ${ }^{\circ}$ 14.040, de 18 de agosto de 2020. Estabelece normas educacionais excepcionais a serem adotadas durante o estado de calamidade pública reconhecido pelo Decreto Legislativo $n^{\circ} 6$, de 20 de março de 2020; e altera a Lei $n^{o}$ 11.947, de 16 de junho de 2009. http:/www.planalto.gov.br/ccivil_03/_Ato2019-2022/2020/Lei/L14040.htm. Acesso em 18 de agosto de 2020.

BRASIL. Constituição (1988). Constituição da República Federativa do Brasil. Brasília, DF, 1988. 


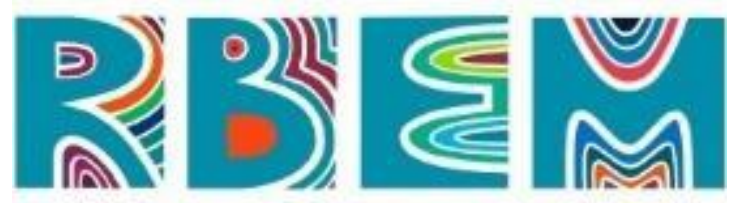

REVISTA BAIANA DE EDUCACAO MATEMATICA

BRASIL. Ministério da Saúde. Portaria $\mathrm{n}^{\circ}$ 188, de 3 de fevereiro de 2020. Declara Emergência em Saúde Pública de importância Nacional (ESPIN) em decorrência da Infecção Humana pelo novo coronavírus. Diário Oficial da República Federativa do Brasil. Brasília, 04 de fevereiro de 2020.

BRASIL. Ministério da educação. Portaria $\mathrm{n}^{\circ}$ 343, de 17 de março de 2020. Dispõe sobre a substituição das aulas presenciais por aulas em meios digitais enquanto durar a situação de pandemia do novo coronavírus - covid-19. Diário Oficial da República Federativa do Brasil. Brasília,18 de março de 2020.

BRASIL. Ministério da educação. Portaria no 345, de 19 de março de 2020. Altera a Portaria MEC no 343, 17 de março de 2020. Diário Oficial da República Federativa do Brasil. Brasília,19 de março de 2020.

BRASIL. Ministério da educação. Portaria n $\mathrm{n}^{\circ}$ 356, de 20 de março de 2020. Dispõe sobre a atuação dos alunos dos cursos da área de saúde no combate à pandemia do COVID-19. Diário Oficial da República Federativa do Brasil. Brasília, 20 de março de 2020.

BRASIL. Ministério da educação. Portaria $\mathrm{n}^{\circ}$ 544, de 17 de março de 2020. Dispõe sobre a substituição das aulas presenciais por aulas em meios digitais, enquanto durar a situação de pandemias do novo coronavírus. Diário Oficial da República Federativa do Brasil. Brasilia, 20 de março de 2020.

BRASIL. Ministério da educação. Parecer CNE/CP n5, de 28 de Abril de 2020. Reorganização do calendário escolar e da possibilidade de cômputo de atividades não presenciais para fins de cumprimento da carga horária mínima anual, em razão da pandemia da COVID-19. Diário Oficial da República Federativa do Brasil. Brasília,01 de junho de 2020.

BRASIL. Ministério da educação. Parecer CNE/CP n9, de 08 de Junho de 2020. Reexame do parecer $\mathrm{CNE} / \mathrm{CP} \mathrm{n}^{\circ} 5$ que tratou da reorganização do calendário escolar e da possibilidade de cômputo de atividades não presenciais para fins de cumprimento da carga horária mínima anual, em razão da pandemia da COVID-19. Diário Oficial da República Federativa do Brasil. Brasília,01 de junho de 2020.

BRASIL. Ministério da educação. Parecer CNE/CP n¹1, de 07 de Julho de 2020. Orientações Educacionais para a realização de aulas e atividades pedagógicas presenciais e Não Presenciais no contexto da Pandemia. Diário Oficial da República Federativa do Brasil. Brasilia,03 de agosto de 2020.

BRASIL. Medida provisória $\mathrm{n}^{\circ}$ 934, de $1^{\circ}$ de abril de 2020. Diário Oficial união República Federativa do Brasil, Poder Executivo, Brasília, DF, $1^{\circ}$ abr. 2020. Seção 1, p.1.

BRASIL. Decreto ${ }^{\circ} 5.622$ de 19 de dezembro de 2005. (Revogado). Regulamenta o art. 80 da Lei no 9.394, de 20 de dezembro de 1996, que estabelece as diretrizes e bases da educação nacional. 


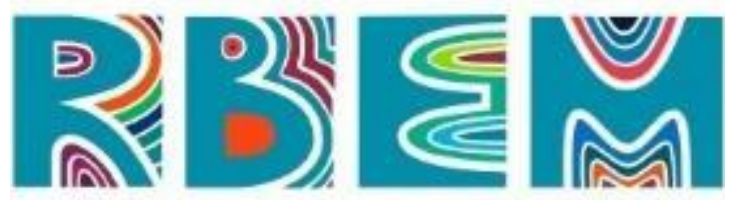

REVISTA BAIANA DE EDUCAÇAO MATEMÁTIGA

BRASIL. Decreto n ${ }^{\circ}$ 9.057, de 25 de maio de 2017. Regulamenta o art. 80 da Lei no 9.394, de 20 de dezembro de 1996, que estabelece as diretrizes e bases da educação nacional.

BRASIL. Ministério da Educação. Base Nacional Comum Curricular. Brasília: MEC, 2017.

CIFUENTES-FAURA, Javier. Consecuencias en los niños del cierre de escuelas por Covid- 19: el papel del gobierno, profesores y padres. Revista Internacional de Educación para la Justicia Social, Madrid, v. 9, n. 3e, p. 1-12, 2020. Disponível em: <https://revistas.uam.es/riejs/article/view/12216/12089>. Acesso em: 22 ago. 2020.

DIAS, Erica; PINTO, Fátima. C. F. Educação e sociedade. Ensaio: Avaliação e Políticas Públicas em Educação, v. 27, n. 104, p. 449-454. Disponível em: https://doi.org/10.1590/s010440362019002701041. Acesso em 18 ago. 2020.

DO CARMO, Vítor Martins; DE MARCO, Fabiana Fiorezi. Ensinando Matemática Com Jogos: Possibilidades e Propostas. Editora Appris, Curitiba-PR, 2019.

DOS SANTOS, Aparecida Raquel Gonçalves; GONÇALVES, Paulo Gonçalo Farias. Videoaulas na aprendizagem em matemática: um olhar para os canais do youtube. Revista Tecnologias na Educação. Ano 9. n.v.19. Julho 2017. Disponível em <http://tecedu.pro.br/wp-content/uploads/2017/07/Art1vol19-julho2017.pdf > Acesso em 16 nov. 2020

FARDO, M. L. A gamificação como estratégia pedagógica: estudo de elementos dos games aplicados em processos de ensino e aprendizagem. 2013. Dissertação (Mestrado em Educação) - Programa de Pós-Graduação em Educação, Universidade de Caxias do Sul,Caxias do Sul, 2013.

INSTITUTO PENÍNSULA. Sentimento e percepção dos professores nos diferentes estágios do coronavírus no Brasil. 2020. Disponível em https://www.institutopeninsula.org.br/pesquisasentimento-e-percepcao-dos-professores-nos-diferentes-estagios-do-coronavirus-no-brasil/. Acesso em: 16 nov. 2020

KAMPF, Cristiane. A geração $\mathrm{Z}$ e o papel das tecnologias digitais na construção do pensamento. Com Ciência. no.131, Campinas, 2011. Disponível em <http://comciencia.scielo.br/scielo.php?script=sci_arttext\&pid=S151976542011000700004\&lng=en\& nrm=iso>. Acesso em 19 ago.2020.

MACHADO, Patricia L. P. Educação em tempos de pandemia: O ensinar através de tecnologias e mídias digitais. Revista Científica Multidisciplinar Núcleo do Conhecimento. Ano 05, Ed. 06, Vol. 08, $\begin{array}{llllll}\text { pp. } & 58-68 . & \text { Junho de } 2020 . & \text { ISSN: } & \text { 2448-0959 }\end{array}$ <https://www.nucleodoconhecimento.com.br/educacao/tempos-de-pandemia > Acesso em: 08 ago. 2020.

MATTAR, João. Metodologias ativas para educação presencial, blended e a distância. Artesanato Educacional, São Paulo, 2017. 


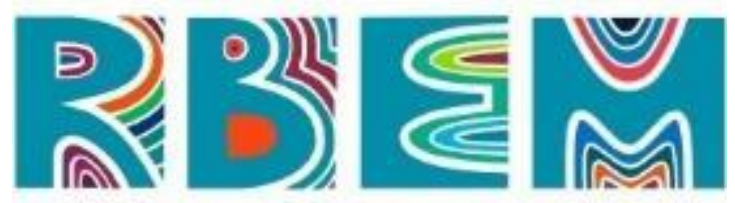

REVISTA BAIANA DE EDUCAÇAO MATEMÁTICA

MELO, Marcela Camila Piccin de. A resolução de problemas: uma metodologia ativa no ensino de matemática para a construção dos conteúdos de" Potenciação e radiciação" com alunos do ensino fundamental. 2020. Dissertação de Mestrado. Universidade Tecnológica Federal do Paraná.

ONU. Coronavírus deixa mais de 776 milhões de alunos fora da escola, diz UNESCO. Nações Unidas, Brasil, 2020. Disponível em: <https://nacoesunidas.org/coronavirusdeixa-mais-de-776milhoes-de-alunos-fora-da-escola-diz-unesco/>. Acesso em: 11 ago. 2020.

PASINI, Carlos G. D; CARVALHO, Élvio de; ALMEIDA, Lucy Hellen C. A educação híbrida em tempos de pandemia: algumas considerações. Rio Grande do Sul. FAPERGS, 2020. Disponível em $<$ https://www.ufsm.br/app/uploads/sites/820/2020/06/Textospara-Discussao-09-Educacao-Hibridaem-Tempos-de-Pandemia.pdf > Acesso em 08 ago. 2020.

PEREIRA, Zeni Terezinha Gonçalves; DA SILVA, Denise Quaresma. Metodologia ativa: Sala de aula invertida e suas práticas na educação básica. REICE: Revista Iberoamericana sobre Calidad, Eficacia y Cambio en Educación, v. 16, n. 4, p. 63-78, 2018.

PRENSKY, M. Digital natives, digital immigrants part 1. On the horizon, v. 9, n. 5, p. 1-6, 2001. Disponível em: <http://www.marcprensky.com/writing/prensky\%20\%20digital\%20natives,\%20digita1\%20immigrants\%20-\%20part1.pdf>. Acesso em: 01 ago. 2019.

TAJRA, Sanmya Feitosa. Informática na Educação: novas ferramentas pedagógicas para o professor na atualidade. Saraiva Educação, São Paulo, 2011.

Artigo submetido em: 16/11/2020

Artigo aceito em: 17/12/2020 